\title{
An Australian Case Study of Delivering a Higher Education Program through Innovative Instructional Technologies
}

\author{
Christopher Klopper, Wendi Beamish, Helen Klieve \\ Griffith University, Australia
}

\begin{abstract}
Sign bilingual education, as an approach to the education of deaf children, has been recognised in Australia for many years. The effective implementation of this approach requires teachers to have a sound linguistic knowledge and communicative competence in Australian Sign Language (Auslan), as well as an understanding of current theory and research in pedagogical practices. This paper reports findings of a case study that utilised design-based research to deliver a specialised program in Australian Sign Language Studies to a group of teachers and teaching assistants working with deaf students throughout the state of Queensland, Australia. The findings recognise that the use of technology was a facilitating factor in the student's learning outcomes rather than an objective of learning. The approach utilised highlights the pedagogical possibilities that innovative instructional technologies for learning offer through the evolution of collaborative use and not simply through revolutionary practice.
\end{abstract}

\section{Introduction}

In Australia and worldwide, higher education institutions are increasingly recognising the effect of quality teaching on student engagement and learning outcomes. Quality teaching involves the intensive use of pedagogy to produce positive student learning outcomes. Dimensions of quality teaching include the effective design of curriculum and course content, a variety of learning environments (e.g., guided independent study, project-based learning, collaborative learning, experimentation), soliciting and using feedback, and effective assessment of learning outcomes. Well-adapted learning environments and student support services have particularly been recognised as contributing to quality teaching and quality learning [5]. The influence of quality teaching has the potential to bring clarity of expectations for student performance, and open new possibilities for increased student satisfaction [11].

The deployment of quality teaching is occurring simultaneously to the call by industry to offer relevant courses by means of innovative instructional technologies. The undertaking by higher education

institutions is to recognise and respond to, not just the technology, but also the veracity of change. Higher education institutions can ill afford to miscalculate the rapidity of change and need to make sure no opportunity passes without the exploration and consideration to improve student learning outcomes. Collectively these changes in how learning and teaching occurs in higher education transpires in a period in which students' needs are becoming increasingly more diverse, teaching staff are under growing pressure to provide high quality educational experiences with fewer resources, and employers' expectations of graduates are not diminishing. However, the underlying assumption that instructional delivery technologies can better cater for the learning needs of today's student population does often not take into account the motivation and expertise of the academics and the context in which they operate. For instance, Australian universities and their academic staff are predominately measured on their research status, which places pressure on staff to invest more time in research outputs over teaching innovation. Under these conditions, the uptake of instructional delivery technologies is, in the authors' experience, patchy and varied. This claim is supported by research reports highlighting that not all university faculties are equally responsive to (a) implementing the range of available learning technologies in their courses [7] and (b) investing monies to build staff capacity in online delivery [5].

In common with many universities across Australia and the globe, Griffith University, the higher education institution where the authors of this article teach, utilises virtual learning platforms or learning management systems (LMS) that provide a web-based framework to handle all online aspects of the teaching and learning process. Blackboard and WebCT are well-known examples of LMS that provide additional functionality beyond providing instructional content because they are also the portal for interactive technologies such as virtual classrooms, facilitation of assessment processes, integration of databases across the entire system and they can track and personalise individual student learning. These systems provide access to a range of instructional delivery technologies such as discussion 
boards, mail systems, live chat, lecture recordings and podcasting along with other course resources [8]. A major goal of utilising these systems is to cater to a more diverse student population and enhance the quality of their university experience while simultaneously aiming to reduce the costs associated with delivering a high standard of tertiary education.

The research project reported in this paper grew out of the need for the Queensland Department of Education and Training (DET) to upskill more staff (teachers and teaching assistants) in Australian Sign Language (Auslan) in order to meet the growing demands for educating deaf students across the state, particularly in rural areas. DET had previously contracted Griffith University to deliver an Auslan program to staff performing similar roles on two previous occasions. Since the last offering in 2010, online course development and learning has advanced substantially [9].

The project adopted a design-based research (DBR) approach with the aim to analyse student learning through the systematic design and study of delivery technologies by "developing, enacting, and sustaining innovative learning environments" [4]. The Design-Based Research Collective argues that designbased research can assist in the creation and extension of knowledge "about developing, enacting, and sustaining innovative learning environments" (p. 5). This Collective group argues the value of attending to the educational context claiming it "is not simple but it produces a better understanding of an intervention, and it can lead to improved theoretical accounts of teaching and learning" p. 7. DBR does not subscribe to any single method, but rather to an explicit overarching concern for using methods that link the processes of enactment to learning outcomes. This approach, therefore, has the potential to generate knowledge that directly applies to efficacy of educational practice. Problematising the context as well as the intervention sets this research method apart from traditional evaluation in which the intervention is normally evaluated against a set of pre-determined standards [15]. Further, the intention of DBR in educational settings is to generate models of successful innovation rather than curriculum artefacts or programs [1]. To this end, the authors of this paper went about producing a model of efficacious instructional technologies in the delivery of an Auslan sign bilingual program to a range of students geographically dispersed across the state of Queensland, Australia.

\section{A description of the program: pedagogical possibilities}

Sign bilingual education as an approach to the education of deaf children, has been recognised in policy and practice in Australia for many years [6]. The successful implementation of this approach requires staff to have a sound linguistic knowledge and communicative competence in Auslan, as well as an understanding of current theory and pedagogical practices. The purpose of the Auslan program of study was to upskill geographically isolated teachers and teacher assistants around the state of Queensland in relation to instructional proficiency and understanding the role of Auslan as the language of instruction for deaf students. Due to the disparity in entry qualifications of the teachers and teacher assistants, the program had to be designed to accommodate this difference between the two student cohorts. Typically, students enrolling in a Graduate Certificate program of study have a Bachelor's degree as pre-requisite. This was the case for the teachers and a requirement of employment for teachers in Australia is to hold a Bachelor's Degree in Education or a Bachelor's degree in an education related field plus a postgraduate qualification in education. For teacher assistants, the requirement for employment is to hold a certificate or diploma. Under the Australian Qualifications Framework (AQF), these qualifications are recognised as AQF level 4 and 5, and qualify individuals for a broad range of specialised knowledge and skills in varied contexts to undertake skilled work. They can be utilised as a pathway for further learning [see https://www.aqf.edu.au/aqf-levels] while the Bachelor degree (AQF level 7), held by the teachers in the program, is a qualification type that enables individuals to apply a broad and coherent body of knowledge in a range of contexts to undertake professional work and is a recognised pathway for further learning at post-graduate level [see https://www.aqf.edu.au/aqf-levels]. Under section 41 of the TEQSA Act [14], a registered higher education provider may apply to TEQSA for authority to selfaccredit one or more courses of study. TEQSA assesses such applications against matters including the Threshold Standards, particularly the criteria for self-accrediting authority

As such, the Auslan program of study needed to differentiate two student cohorts by design and level of assessment requirements. This arrangement was achieved through consultation with all members of the academic teaching team. In keeping with AQF requirements, the program learning outcomes were clustered around two key domains: knowledge and skill acquisition, and the application of knowledge and skills.

Graduating teachers of the Graduate Certificate in Auslan Studies were provided with opportunity to:

(a) further develop a range of specialised knowledge and skills, including

- knowledge of the linguistics features of Auslan and how the language may impact on the forms of curriculum and pedagogy used in sign bilingual classrooms and in mainstream contexts. 
- cognitive skills to review, analyse, consolidate and synthesis knowledge of sign bilingual pedagogy and identify specific teaching strategies to use with students across the Key Learning Areas.

- technical and communication skills to identify, analyse and annotate specific linguistic features of Auslan in a range of texts.

- cognitive skills to critically evaluate and reflect on knowledge relating to sign language acquisition, sign bilingualism and pedagogy and communication skills to transfer this complex knowledge to a variety of audiences.

(b) demonstrate the application of knowledge and skills

- $\quad$ by initiating, assessing, planning, implementing and evaluating specific sign bilingual pedagogy and curriculum design for deaf or hard of hearing students using Auslan in varied educational settings.

- through expressive and receptive proficiency across a range of Auslan texts for both instructional and social purposes.

By comparison, Graduating teaching assistants of the Continuing Certificate of Auslan Studies were provided with opportunity to:

(a) acquire a range of specialised knowledge and skills, including

- Knowledge of key grammatical structures unique to sign language with a particular focus on phonology, morphology, and syntax.

- cognitive skills to consolidate and synthesis knowledge of Auslan linguistics and the AuslanEnglish continuum to inform instruction, particularly in the area of reading.

- technical and communication skills to identify and compose Auslan texts for conversational and instructional purposes. skills:

(b) demonstrate the application of knowledge and

- by planning and implementing a professional practice project in the workplace.

- through expressive and receptive proficiency across a range of Auslan texts for both instructional and social purposes.

The Auslan program, comprising four courses (Auslan 1 through 4), was executed over two years across four consecutive teaching periods of 13 weeks Course content was sequenced to reflect the progressive nature of language learning, and extended into forms of pedagogy and curriculum design. These elements provided both broad and specific reference points for understanding the applications of Auslan in schools. Participating staff were introduced chronologically to the core design features of the language: grammar, central elements of sign formation, expressive and receptive use of the language, sociolinguistic variations and considerations of situational factors in sign language use. Expressive and receptive practice with the Auslan language was maintained within and across courses. Additionally, procedures for continuous assessment and feedback were included to support and enhance learning and Auslan proficiency. The first three courses afforded participating staff one day per week of release from school duties across the university semester to engage in a combination of lectures, tutorials, and independent study via a mix of face-toface, videoconferencing, and on-line delivery modes. For these courses, the teaching period culminated in a face-to-face intensive week of Auslan language exposure and practice, using language "immersion" techniques as well as explicit teaching of linguistic features and structures.

The final course afforded staff one day per week of release across the university semester to design and implement an action research project in schools as summative assessment. This experienced facilitated participants applying their learning's in a real world situation. They all identified a small intervention which they then undertook, with reporting on their observations on the success of the intervention process. While this task was applied at appropriate levels for the two groups, it did require a shift from a theoretical learning to higher levels of understanding through the real world implementation of change.

\section{Practicalities of innovative instructional pedagogies}

The program followed a five-stage iterative process for gathering data from students about their competence and experience of online learning. At the commencement of the program, baseline data was collected and then sequentially at the end of each course. All data was collected by means of online survey.

At collection point one, all participating students $[\mathrm{n}=26]$ were asked to respond to items concerning computer efficacy, attitudes, and technology-related anxieties adopted from The Computer Technology Use Scale (CTUS) [3]. Figure 1 identifies a number of items from initial responses to the CTUS. A notable level of agreement was indicated on the item regarding the need for time and persistence in getting familiar with computer systems (mean 5.55). Students also agreed with the statement that they could use help structures to sort out problems (mean 4.77), which suggested an overall level of basic computer technology competence. 


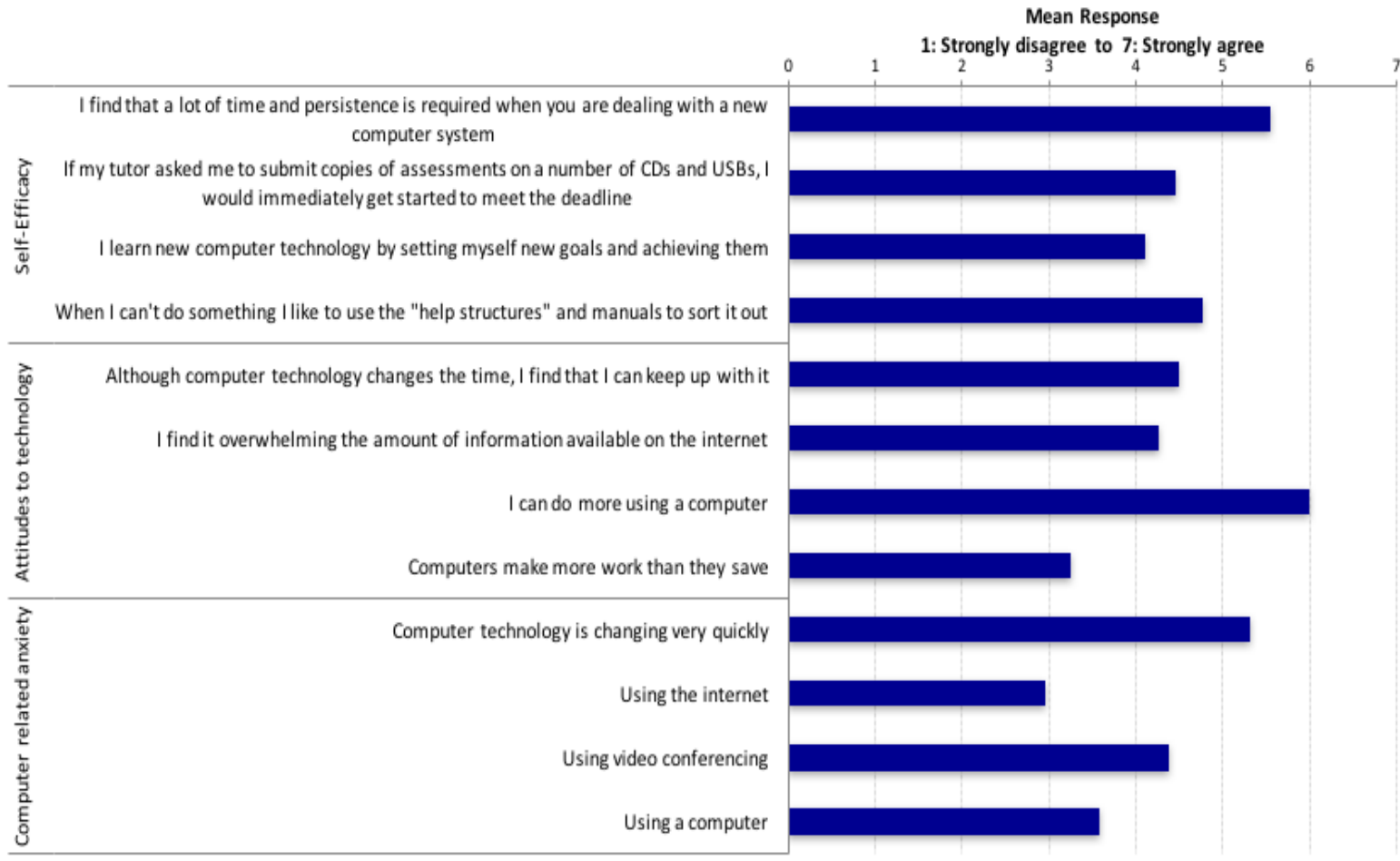

Figure 1. Selected response to 12 of the 49 items on the CTUS

Table 1 . Summary of data collection strategies by period, and analytic approaches

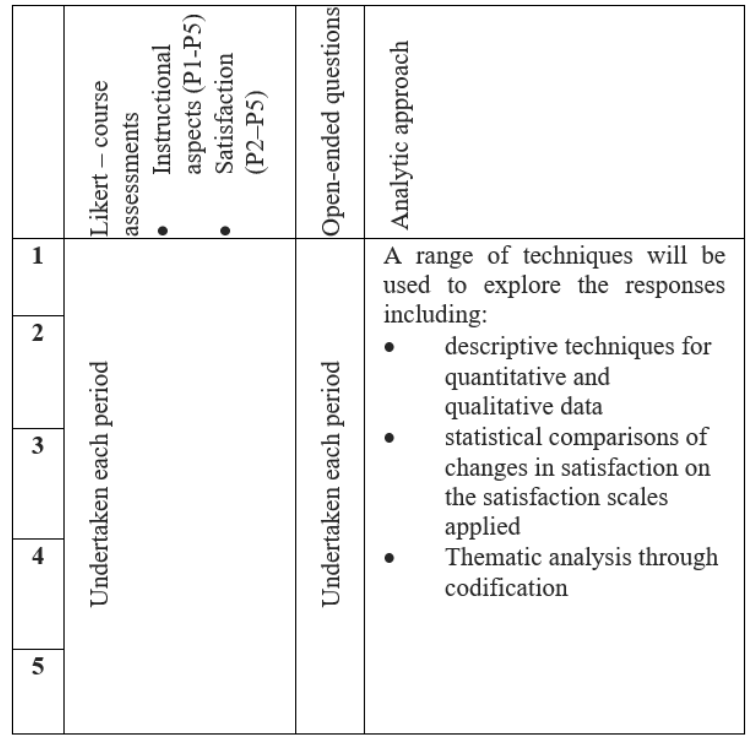

At collection points two through five, participating staff were asked to respond to routine evaluations at the completion of the courses utilising Griffith Student Evaluation of Courses Survey Data. Griffith is committed to a University-wide approach to gathering feedback from students about teaching and courses, the implementation of which are supported by processes that are effective, efficient, comprehensive, systematic and sustainable. Griffith University uses a wide range of methods to gather data to evaluate teaching and its courses. The data are used routinely as part of Griffith's ongoing quality assurance processes and to support scholarship in teaching. One of the methods of gathering data is to collect feedback on courses and teaching from students using survey instruments.

Table 2. Mean Scores for Selected Items

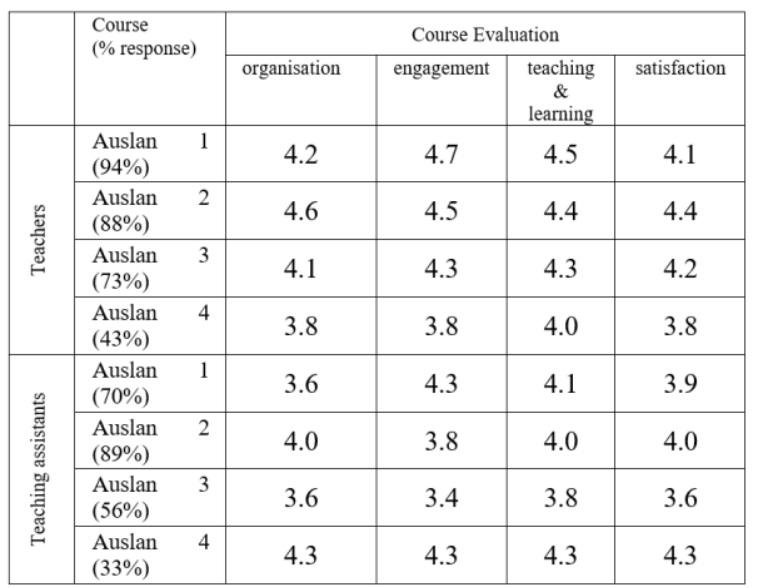

Completion of a feedback instrument or participation in a feedback process by a student is taken as consent to the use of the data provided in the ways indicated. In all cases, the anonymity of the participants who 
provide feedback to the University is maintained. Table 2 presents scores assigned by the two cohorts (teachers and teaching assistants) on a 5-point rating scale. Taken together, these positive scores endorse the lecture and tutorial formats, the design of websites and online learning features, and overall satisfaction with the learning outcomes of the program.

Students also responded to an online satisfaction survey with nine Likert-style questions and three open-ended questions related to experienced challenges and benefits that represented items from surveys evaluating web-based professional development programs [2], [12]. Figure 2 summarises the overall patterns from the group. The first two items, the most positive in response, indicate that staff found the course site easy to navigate - with a clear improvement after the first period. Also they agree that there were good opportunities to interact with the instructor - through various mediums. In line with the comments on Figure 1, there seemed to be no marked change regarding confidence with the internet, with item 8 "this class has made me feel more comfortable using the internet" showing a neutral level across the four semesters of study. While there was a very clear response to item 9 (people learned as well on-line as in a face-to-face class), this is not surprising, but a number of participating staff also recognised that a fully face-to-face learning environment was not an option.

At each data collection point of the Griffith Student Experience of Course Survey, students were invited to provide commentary in open ended question format. All responses were treated as data. Data analysis is the part of qualitative research that most distinctively differentiates from quantitative research methods. It is not a technical exercise as in quantitative methods, but more of a dynamic, intuitive and creative process of inductive reasoning, thinking and theorizing. The process of analysing qualitative data predominantly involved coding or categorising

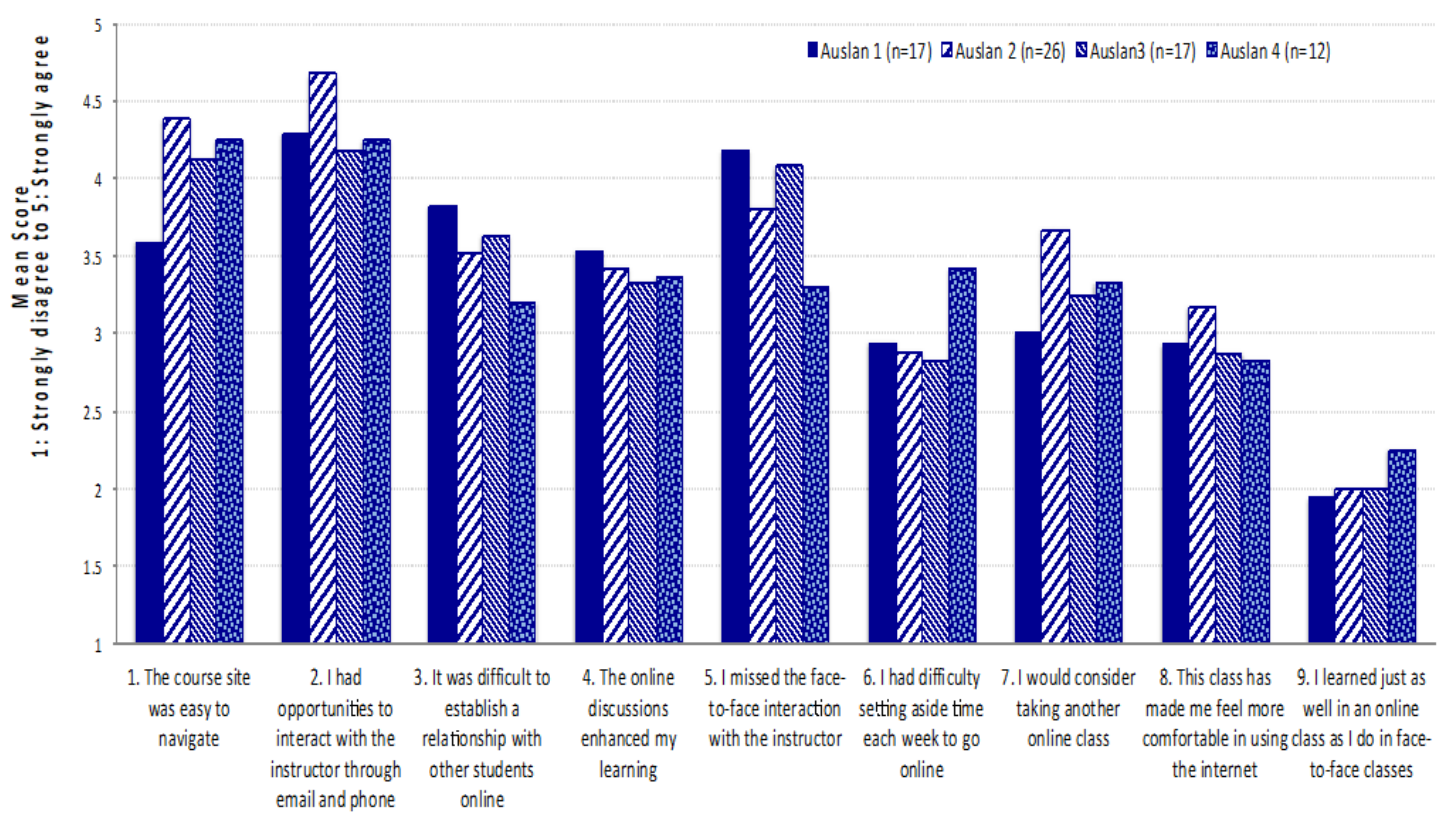

Figure 2. Participant mean scores to satisfaction survey

the data. It involved making sense of the data by reducing the volume of raw information, followed by identifying significant patterns or themes, and finally drawing meaning from data and subsequently building a logical chain of evidence. Here follows embedded text from the student responses elaborating and underpinning the key themes identified.

\subsection{Modes of delivery for learning}

At the outset of the delivery of the program, both university staff and participating students were challenged by the technology on hand. Weekly workshop delivery typically involved a lecturer presenting to a group of students in situ communicating via means of an Auslan interpreter and support lecture slides. Three virtual groups attended this same workshop facilitated by video conferencing technology and Collaborate virtual classrooms. A second interpreter was present at the site of the lecturer to watch for any response from the students attending in these remote locations and was on hand to translate. When considering the student learning outcomes of the program, which targeted building specific skill capacity in a group of specialised students, it is important to recognise that the use of technology was a facilitating factor rather than an objective. It became apparent that for both the students and academic teaching staff the combinative and simultaneous deployment of innovative pedagogical techniques improved over time. 
Technology issues did not impact as much on the course delivery this time as in previous semesters but it was still a challenge occasionally for people off site (Student A). However, in the $4^{\text {th }}$ offering, rather than weekly sessions there were two whole day intensive group workshops, firstly focusing on (i) planning the intervention and understanding literature; and (ii) developing the final intervention report. Outside these periods students interacted with the teaching staff individually on their project. While for this last course there were only 2 formal sessions, these did include all students in face to face sessions.

Too often one's frame of reference and prior experiences limit the potential to embrace new or alternative approaches to tried and tested practices. This is most evident in relation to teaching and learning styles. For most of the students in the program, tertiary study was new or felt quite 'new' as many years had transpired since previous study had been undertaking. This posed a great challenge for all in the program as further study was not only new but the approach to the teaching and learning was also identified as being new for the student cohort. Students repeatedly called for more face-to-face teaching and less virtual mediated learning: I would have liked more face to face lectures or alternate online sessions in the weeks there was no face to face to discuss assignments, content, talk with lecturers (Student C) and It was so good to have all classes face to face in the final semester. This method of learning has much more impact. I was also encouraged to believe in myself more - so thank you. As a result of this course I feel much better prepared to work with Auslan users! (Student D).

The first three course offerings culminated in a week long residential teaching period and reported high levels of satisfaction: Block week was an amazing experience. So valuable for all who attended, no matter what their signing level was. The quality of our lecturers has been exceptional (Student $\mathrm{N}$ ). However, despite the expressed feeling that face-toface should be the preferred mode of delivery, students from geographically isolated areas in Queensland, Australia did express: While video conferencing was challenging at times it was of great benefit not to have to travel long distances to access the course (Student E) and Can see now how effective videoconferencing is (Student $\mathrm{C}$ ).

\subsection{Depth of learning}

Breadth of learning refers to the full span of knowledge of a subject whereas depth of learning refers to the extent to which specific topics are focused upon, amplified and explored. Griffith University in consultation with the DET representative and subject matter experts designed the Auslan program for delivery based on the identified depth of learning, assumed knowledge and skills of the prospective students. This was affirmed through student feedback: Significant improvement of my professional knowledge and understanding about deaf education. Definite changes to my practice (Student D) and Learning more and improving how I work with deaf students (Student H).

A strength of the program of study was the immersion week held at the culmination of each course offering witnessed by this student comment Even though the days were long, it was the best learning experience to be in the classroom, compared to being a student offsite (Student $\mathrm{N}$ ). During the immersion week students got to experience first-hand the complexities of teaching Auslan and the joy it unlocks. Great opportunity to improve my signing in a real life context. Good opportunity to talk over classroom teacher issues and share knowledge (Student M), and Time out to focus on improving knowledge and skills with others who have similar passion (Student D).

After each course offering the teaching team took time to reflect on the teaching and learning experiences offered, and where appropriate made adaptations to and for the subsequent delivery of courses. Level of confidence in the depth of learning grew over the duration of the program, and student affirmations reinforced this. The benefits of this course include learning about relevant pedagogy and practice for use in teaching Deaf children how to read as well as learning a lot of Auslan (Student D).

\subsection{Barriers to learning}

The adult learner has many responsibilities that must be balanced against the demands of and barriers to learning. Some frequently identified barriers include (a) lack of time, (b) lack of confidence, (c) lack of information about opportunities to learn, (d) scheduling problems, (e) lack of motivation, and (f) "red tape" [10]. The participating students in the Auslan program were by no means immune to such barriers.

The educational environment is perhaps the most apparent area of academic influence. It may be understood to encompass the following areas:

- teaching styles and educational choices that academic teaching teams make in the design and set up of classroom experiences. In particular, a clash between a teacher's teaching styles and the learner's learning style may be a barrier to student success, and a struggle to make space for learning to occur outside designated program delivery hours. This was felt by many students who had to manage and negotiate multiple agenda: finding time to make the course a priority (Student A) and time commitment taken for postgrad studies (Student C). 
- the classroom climate, which includes the nature of teacher-student interaction, the teaching/learning activities and student learning feedback. The classroom climate was challenging with the mix of in-person and virtual attendance. The students felt this and regularly reported their frustration: Having some people in the room and others off site made life difficult for everyone. Balancing a full time teaching load with the assessment was difficult (Student E).

- Students feeling that teachers are unavailable or unapproachable has been shown to impact on their academic confidence and in turn to influence their academic performance [13]. Student F shared: not having regular, face-to-face, contact with lecturers. The geographic dispersion resulted in the dominant mode of contact with the academic teaching team to be via email. For many in the two cohorts this was felt to be impersonal, and understandable as for many it was their first attempt at tertiary education and would have valued positive reaffirmation in person and not via electronic communication. Considering the program of study empowered students to communicate in a hearing world, it's not surprising that students wanted to benefit from an in-person style communication.

- the curriculum, including the design of the program and course and, in particular, the extent to which students can see relationships between courses and across their program. It also relates to the way in which the course is organised, including the time devoted to particular subject areas.

- assessment, which might logically seem to fit with curriculum but is separated here to provide emphasis to the high priority that students put on assessment as a 'driver' of their learning and hence the barrier that it may become.

\subsection{Collegial learning and sense of connection}

Griffith University's principles to promote excellence in learning and teaching practices express the University's values and commitment as a learningcentred, research university. This is coupled with the assurance of quality teaching staff, whether they be full-time academic appointments or contracted sessional staff with relevant industry-experience.

A number of the identified barriers to learning can influence an adult learner's sense of academic integration [We will miss the camaraderie that developed between the students undertaking the course, particularly during the Block Weeks. WE learned a lot from other students as they came from a variety of programs supporting Students learning
Auslan (Student $\mathrm{H}$ )] and social integration [Great that it is accessible to all staff over Queensland (Student E)] or, conversely, can contribute to academic isolation [challenging for those off campus as they found it more difficult to feel part of the group. I would have found it difficult if I was in a room by myself (Student B)].

The decision to offer learning through a combination of sequenced weekly teaching episodes culminating with an intensive in residence teaching week provided invaluable opportunities for a sense of connection and purpose to establish. Participating staff remarked favourably of the intensive in residence teaching weeks and considered these times as a hallmark of delivery in this program. The crosspollination of ideas between teachers and teacher assistants was an unexpected outcome, providing the opportunity for collegial learning and a sharing of experiences contributing to a rich tapestry of learning episodes.

\subsection{Expertise of teaching staff}

Griffith University's principles to promote excellence in learning and teaching practices express the University's values and commitment as a learningcentred, research university. This is coupled with the assurance of quality teaching staff, whether they be full-time academic appointments or contracted sessional staff with relevant industry-experience. Reinforced by student feedback such as: The lecturers and interpreters for this course have been amazing (Student B) and Great learning opportunity. Thank you to all the tutors and lecturers for a terrific opportunity (Student L).

\section{Summation}

\subsection{Lessons learnt}

- The whole group sessions across the program, while included for teaching purposes, were also very valuable in developing a strong cohort that were supportive across the entire program.

- More could have been done to develop a Community of Practice between teachers and teaching assistants (e.g., by providing problemsolving co-operative learning activities in tutorials rather than general group discussions).

- The research component, assessing a pedagogical intervention, while seen as valued by participants and contributing to learning by participants, could have been more effective through greater preparation in prior courses.

- Anxiety experienced by some teaching assistants in completing lengthy assignments could have 
been reduced through the introduction of short but frequent knowledge-based online quizzes.

- Technology for learning and teaching requires an evolutionary, scaffolded process of learning, and in some cases un-learning, in order for the technology to effectively support learning and teaching.

- The affirmation of face-to-face delivery over innovative instructional techniques might have been cohort specific, but affirms the need for establishing and maintaining strong relationships in learning and teaching built on one-to-one interactions.

- The value and role of the collective through collaborative learning was key in this program, and should be a feature of all curriculum design and delivery models.

\subsection{Conclusion}

When considering the outcomes of the program, which targeted building specific skill capacity in two cohorts of specialised staff, it is important to recognise that the use of technology was a facilitating factor rather than an objective. The inclusion of many geographically isolated teachers and teaching assistants in the program was only possible by the program being completed in mixed-mode delivery. The design included several intensive teaching periods to build a cohesive group and support the use of delivery technologies for learning. At the beginning of the program, participating staff indicated a moderate level of skill and capacity with using computer technologies. At the end of the program, data collection gave a positive picture of outcomes, moderated by a clear preference for the face-to-face environment. Further, a number of graduates demonstrated high quality learning outcomes that would support aspirations for further study. This endorsement by graduates was congruent with the satisfaction expressed by DET (program sponsor) and aligned with the University's expectation of advancing innovations in learning and teaching. Taken together, the approach utilised in this program highlights the pedagogical possibilities that delivery technologies for learning offered in Higher Education.

\section{References}

[1] Brown, A. L., \& Campione, J. C. Psychological Theory and the Design of Innovative Learning Environments: On Procedures, Principles, And Systems. In L. Schauble, \& R. Glaser (Eds.), Innovations in Learning. Mahwah, $\mathrm{NJ}$ : Erlbaum, 1996, pp. 289-325.

[2] Chen, D., Klein, M. D., \& Minor, L. Interdisciplinary Perspectives in Early Intervention: Professional Development in Multiple Disabilities through Distance
Education. Infants \& Young Children, 22, 2009, pp. 146158.

[3] Conrad, M., \& Munro, D. Relationships between Computer Self-efficacy, Technology, Attitudes and Anxiety: Development of the Computer Technology Use Scale (CTUS). Journal of Educational Computing Research, 39,1, 2008, pp. 51-73.

[4] Design-based Research Collective. Design-based Research: An Emerging Paradigm for Educational Inquiry. Educational Researcher. 32, 2003, pp. 5-8.

[5] Henard, F., and Roseveare, D. Fostering Quality Teaching in Higher Education: Policies and Practices. OECD Publishing, 2012.

[6] Johnston, T., \& Schembri, A. Australian Sign Language (Auslan): An Introduction To Sign Language Linguistics. Cambridge University Press, London, 2007.

[7] Kaznowska, E., Rogers, J., and Usher, A. The State of ELearning in Canadian Universities, 2011: If Students Are Digital Natives, Why Don't They Like E-Learning? Higher Education Strategy Associates, Toronto, 2011.

[8] Klopper, C., Gillet, A. \& Ghada, S. Technology for learning: Something old, something borrowed, and something new. In C. Nygaard, J. Branch, P. Bartholomew, $\&$ A. Horsted, A. (Eds.) Innovative Teaching and Learning in Higher Education, Faringdon: Libri Publishing, 2017, pp. 177-187.

[9] Laurillard, D. E-Learning in Higher Education, in P. Ashwin (Ed.) Changing Higher Education: The Development of Learning and Teaching, Routledge Falmer, London, 2006.

[10] Lieb, S. Principles of Adult Learning. 1991, http://www.petsalliance.org/sites/petsalliance.org/files/Lie b\%201991\%20Adult\%20Learning\%20Principles.pdf (Access Date: 9 June, 2017).

[11] Popenici, S, and Millar, D. Writing Learning Outcomes: A Practical Guide for Academics. The University of Melbourne, 2015.

[12] Rakap, S., Jones, H. A., \& Emery, A. Evaluation of a Web-based Professional Development Program (Project ACE) for Teachers of Children with Autism Spectrum Disorders. Teacher Education and Special Education, 38, 2015, pp. 221-239.

[13] Ramsden, P. Learning to Teach in Higher Education (2nd ed.). Routledge Falmer, New York, 2003.

[14] Tertiary Education Quality and Standards Agency Act 2011. No. 73, 2011. Compilation No. 8. Compilation date: 13 December 2014.

[15] Worthen, B.R., Sanders, J.R., \& Fitzpatrick, J.L. Educational Evaluation: Alternative Approaches and Practical Guidelines. (3rd ed.). Boston: Allyn \& Bacon, 2004 